\title{
ESTEREÓTIPOS BÁSICOS \\ E ESTEREÓTIPOS OPOSTOS: \\ REPRESENT AÇÕES DO \\ DIALETO CAIPIRA \\ EM DISCURSOS \\ INSTITUCIONAIS \\ E CIENTÍFICOS
}

\section{ESTEREOTIPOS BÁSICOS Y ESTEREOTIPOS OPUESTOS: REPRESENTACIONES DE DIALECTOS DE CAIPIRA EN DISCURSO INSTITUCIONAL Y CIENTÍFICO}

BASIC STEREOTYPES AND OPPOSING STEREOTYPES: REPRESENTATIONS OF THE CAIPIRA DIALETTE IN INSTITUTIONAL AND SCIENTIFIC SPEECH

Lígia Mara Boin Menossi de Araujo* Universidade Federal de São Carlos

Marco Antonio Almeida Ruiz**

Universidade de São Paulo | Ribeirão Preto

RESUMO: Neste artigo, com base na dimensão representacional da linguística popular, proposta por Achard-Bayle e Paveau (2008), inicialmente, objetivamos testar a fecundidade da teoria dos estereótipos básicos e opostos, proposta por Possenti (2010) em discursos de diferentes campos, produzidos sobre o dialeto caipira. Na sequência, refletimos como essa teoria brasileira de discurso poderia contribuir para o burilamento do olhar sobre esse dialeto no ensino e, por conseguinte, compreender a circulação do estereótipo do caipira em nossa sociedade. Com base nesses objetivos, mobilizamos como corpus de análise, primeiramente um conjunto de enunciados postados em site oficial, destinado a professores de língua portuguesa. Tais enunciados constituem um plano de aula que tem como temática o caipira e seu dialeto. Como corpus auxiliar, frequentamos também alguns dos discursos científicos provenientes dos estudos do Projeto História do Português Paulista, o Projeto Caipira

\footnotetext{
* Doutora em Linguística pelo Programa de Pós-Graduação em Linguística da UfSCar e Bolsista PNPD da CAPES. E mail: ligiamenossi@gmail.com.

** Doutor em Linguística pelo Programa de Pós-Graduação em Linguística da UFSCar e em Sociologia pela Escola de Altos Estudose Ciências Sociais de Paris. E-mail:marcoalmeidaruiz@gmail.com.
} 
que, nas últimas décadas, produziu trabalhos que buscam a desmistificação do estereótipo do caipira como um sujeito matuto ou ingênuo, bobo ou inteligente etc.

PALAVRAS-CHAVE: Discurso. Estereótipo. Dialeto caipira. Ensino. Linguística popular.

RESUMEN: En este artículo, basado en la dimensión representativa de la lingüística popular, propuesta por Achard-Bayle y Paveau (2008), inicialmente buscamos probar la fertilidad de la teoría de los estereotipos básicos y opuestos, propuesta por Possenti (2010) en discursos de diferentes campos producidos sobre el dialecto caipira (Portugués). A continuación, reflexionamos sobre cómo esta teoría brasileña del discurso podría contribuir a agudizar el aspecto de este dialecto en la enseñanza y, por lo tanto, a comprender la circulación del estereotipo caipira en nuestra sociedad. En base a estos objetivos, nos movilizamos como un corpus de análisis de las primeras declaraciones publicadas en un sitio web oficial, dirigido a profesores de portugués. Tales declaraciones constituyen un plan de lección que tiene como tema el campesino sureño y su dialecto. Como corpus auxiliar, también asistimos a discursos científicos de los estudios de la Historia del Proyecto Paulista Portugués, el Proyecto Caipira que, en las últimas décadas, ha producido obras que buscan desmitificar el estereotipo caipira como un tema tonto o ingenuo, tonto o inteligente, etc.

PALABRAS CLAVE: Discurso. Estereotipo. Dialecto caipira. Enseñanza. Lingüística popular.

ABSTRACT: In this article, based on the representational dimension of popular linguistics, proposed by Achard-Bayle and Paveau (2008), we initially aimed to test the fertility of the theory of basic and opposite stereotypes, proposed by Possenti (2010) in discourses from multifarious fields produced about the caipira dialect. Moving on, we reflect on how this Brazilian theory of discourse could contribute to look more carefully on this dialect in teaching practices and, therefore, to understand the circulation of the caipira stereotype in our society. Based on these objectives, we mobilized, as the main corpus of analysis, utterances posted on an official website aimed at Portuguese language teachers. Those sentences are part of a lesson plan that has as its theme the caipira and their dialect. As an auxiliary corpus, we also draw on scientific discourses from the studies of the History of Portuguese Paulista Project, the Caipira Project which, in the last decades, has produced studies that seek to demystify the caipira stereotype as foolish or naive, silly or an intelligent subject.

KEYWORDS: Discourse. Stereotype. Caipira dialect. Teaching. Popular linguistics.

\section{INTRODUÇÃO}

O português caipira, considerado por muitos estudiosos falar típico do interior paulista, tem sido objeto de estudos e pesquisas de diferentes linguistas e não linguistas na contemporaneidade. No campo da Sociolinguística Educacional, por exemplo, um dos caminhos trilhados é a sua representação no imaginário social com o fito de desmistificar o "erro" como ponto fundante da língua por meio do ensino da variação e mudança, reinterpretando, de certo modo, os conceitos de se falar "certo" ou "errado", a partir de uma identidade cultural que lhe é própria, a caipirice. Já no campo da análise do discurso, podemos observar os estudos acerca da identificação de uma "representação coletiva cristalizada" (AMOSSY, 2004, p. 215) do caipira, marcada pela propagação de estereótipos, no interdiscurso, esses (re)contados diferentemente - e na maioria das vezes, de cunho pejorativo - ressaltando determinados traços - burro ou inteligente, matuto ou esperto, bobo ou ingênuo, entre outros - supostamente característicos desse sujeito interiorano.

Trata-se, pois, de um lado, de diferentes interpretações de sua figura ao longo da história e, de outro, dos estereótipos e das representações sobre o seu falar caipira, materializados enunciativamente em piadas, chistes, anedotas e outras formas humorísticas, que buscam caçoar de seus usos linguísticos, utilizando-se de recursos “menos" ofensivos, por meio do humor, trazendo o riso como resultado esperado.

Com efeito, é possível constatar diferentes simulacros do caipira sendo construídos "a torto e a direito", cujo objetivo é marcar uma dada característica linguística que tanto o define, o seu dialeto. De tão oportuno para os estudos da língua portuguesa, e de tão marcante para a história de nossa cultura interiorana, vemos tal dialeto caipira ser objeto de reflexão, como forma de marcar 
positivamente um dado falar regional e ressaltar as características que lhe são próprias, tais como a sua presença nas histórias em quadrinhos.

Para este artigo, procuramos pensar como o estereótipo do caipira pode ser entendido por meio de duas perspectivas distintas: daqueles que a tomam como uma representação cristalizada, como o caipira ainda de Amadeu Amaral, em 1920, ou a partir dos estudos oriundos do Projeto História do Português Paulista que, para além de pensar o caipira como iletrado ou matuto, esperto ou malandro, indolente ou preguiçoso, o enxerga como o genuíno brasileiro, o falante de uma variedade que se perpetua e que tem tomado lugares outros na sociedade.

Atualmente, a linguística brasileira conta com modelos teórico-metodológicos próprios que tomam a linguagem como objeto de sua reflexão. Trata-se, desse modo, de reconhecer que pesquisadores brasileiros, para além de terem bebido nas fontes teóricas estrangeiras, adaptaram essas fontes e começaram a criar seus próprios arcabouços epistemológicos. Com base nessas afirmações e, ainda, considerando que há importantes pesquisadores brasileiros que propuseram a elaboração de teorias brasileiras de linguagem (BARONAS, 2015), alicerçamos nossas questões nos pressupostos teóricos da análise do discurso de matriz francesa, sobretudo, por meio de uma vertente de teoria brasileira de linguagem, a teoria dos estereótipos básicos e opostos conjeturada por Sírio Possenti (2010). Nosso corpus de análise é composto por enunciados que são encontrados em um site, responsável por divulgar conteúdos e atividades para o ensino de português, para professores - o Portal do Professor (OLIVEIRA; PRAZERES, 2018) -, vinculado ao Ministério da Educação. Mobilizamos, em especial, o plano de aula que traz como temática de estudo o caipira e o seu dialeto; além disso, numa espécie de corpus lateral, selecionamos discursos científicos provenientes dos estudos do Projeto História do Português Paulista (PHPP), o Projeto Caipira ${ }^{1}$, que desmistificam o olhar estereotipado sobre caipira, introduzindo questões interessantes como, por exemplo, tratar de certa variedade da língua falada e não apenas olhá-la como um "erro".

Nesse caminho, objetivamos também testar a fecundidade da proposta por Possenti (2010) nos discursos produzidos sobre o dialeto caipira. Pensamos, assim, em como essa teoria brasileira de discurso poderia contribuir para o burilamento do olhar sobre esse dialeto no ensino para compreensão da circulação do estereótipo do caipira ${ }^{2} \mathrm{em}$ nossa sociedade por meio das diferentes representações pré-construídas e cristalizadas no imaginário coletivo brasileiro. Para tanto, estaremos norteados pelo seguinte questionamento: como retratar tal variedade da língua portuguesa, em meio ao conjunto de diferentes dialetos brasileiros sem, contudo, esbarrar nessa construção negativa dos estereótipos do caipira?

\section{DA ESCRITA PARA A FALA: ESTEREÓTIPOS E SIMULACRO}

As proposições de Possenti (2010), embora busquem subsídios teóricos em Gênese dos discursos, de Dominique Maingueneau (1984), sobretudo no que concerne à noção de simulacro, avançam os seus postulados, perquirindo um tratamento de dados bem originais, composto por piadas. O autor tenta associar as piadas à questão da identidade, elencando aspectos que possam representar a identidade de um povo com base em um material humorístico. As piadas, segundo o autor, funcionariam - no que diz respeito à estereotipia - baseando-se em um traço que é assumido por uma pessoa ou determinado grupo social (estereótipo básico) para produzirem e fazerem circular o seu oposto mais rebaixado possível (o estereótipo oposto ou simulacro invertido ${ }^{3}$. A

\footnotetext{
${ }^{1}$ O Projeto tem como objetivo contribuir não só para organizar diacronicamente materiais sobre a língua portuguesa, mas também compreender os sujeitos envolvidos e suas diferentes perspectivas sobre os acontecimentos e, por consequência, agregar reflexões outras sobre os falares brasileiros. A íntegra dos objetivos pode ser encontrada no seguinte endereço: http://phpp.fflch.usp.br/oprojeto. Acesso em: 10 set. 2019.

${ }^{2}$ Em nosso cotidiano, podemos encontrar nas piadas, por exemplo, a fonte de propagação de um estereótipo preconceituoso do falar caipira, reafirmando traços que foram (e ainda estão) atrelados à figura desse sujeito do interior, como alguém à margem da sociedade civilizada.

${ }^{3}$ Com o objetivo de apreender o discurso por meio da interdiscursividade, Maingueneau (2008) propõe a hipótese de que o interdiscurso precede o discurso. Essa hipótese volta-se ao que o autor denominou de competência discursiva. Com isso, o discurso produzido traduz outros discursos, associados pela relação do interdiscurso corrente. O enunciador, "[...] quando [...] confrontado com seu Outro [...], é condenado a produzir simulacros desse Outro, e simulacros que são apenas seu avesso" (MAINGUENEAU, 2008, p. 55). Dessa forma, essa construção, por meio de outros discursos, transforma-os a ponto que sua presença refere-se ao um "simulacro" que o discurso primeiro constrói em relação aos demais "pré-existentes".
} 
hipótese levantada pelo estudioso é a de que a identidade construída está sempre representada nas piadas por meio de estereótipos. Segundo o pesquisador brasileiro:

Assumo [...] que o fato de que a identidade é uma representação imaginária não significa necessariamente que não tenha amparo no real. Significa apenas que não é seu espelho, sua cópia. [...] o estereótipo também deve ser concebido como social, imaginário e construído, e se caracteriza por ser uma redução4 (com frequência negativa), eventualmente um simulacro. (POSSENTI, 2010, p. 40)

Com base nesse princípio teórico, quando se busca rebaixar o outro, promovendo características negativas, tem-se que os estereótipos são construídos por aquele que traduz o discurso do outro a partir das categorias do mesmo, isto é, a partir de um imaginário socialmente construído - estereótipo básico -, o sujeito produtor inverte a característica positiva, (des)construindo a imagem - e com isso, muitas vezes a identidade - para o valor negativo - estereótipo oposto -, rebaixando-o promovendo, assim, o riso como resultado.

A partir dessa hipótese teórica, da passagem do estereótipo básico ao estereótipo oposto, Possenti toma como material de análise, dentre outras, as piadas de gaúcho. O estereótipo básico que é posto em questão é, em grande parte, a gauchice, ou seja, coloca-se como temática os traços que constituem o imaginário do povo gaúcho: ser hospitaleiro, livre, despachado, pouco refinado, gostar de churrasco, ser "macho" e fazer questão de frisar sua macheza no seu discurso. Essas características, sobretudo o traço da macheza, constituem o estereótipo básico, tratado de maneira peculiar nas piadas. Ser macho, nas piadas de gaúcho será o ponto crucial para a concretização de novos estereótipos (opostos) "desqualificando" a figura do gaúcho, representando-o de maneira inversa, mais direta e picante: “[...] ele não será franzino e medroso, mas homossexual passivo" (p. 44). Vejamos um exemplo trazido por Possenti, (2010, p. 42):

\footnotetext{
Um deputado gaúcho teria dito, há algumas décadas, numa sessão da Câmara:

- No Rio Grande do Sul só tem macho!

- Ao que um deputado mineiro teria respondido:

- Pois em Minas, metade é homem, metade é mulher, e a gente tem se dado muito bem.
}

Na piada em questão, notamos que o estereótipo básico é posto em funcionamento pelo próprio gaúcho: "no Rio Grande do Sul só tem macho!". Ao mobilizar tal discurso, realça o traço da macheza como uma marca de identidade do povo gaúcho. Por outro lado, o estereótipo oposto, nesse caso, é colocado em cena pela construção da imagem do outro - do sujeito mineiro - que faz uma representação positiva de seu povo: o mineiro, ao contrário do povo gaúcho, gosta de mulher, não de macho. Trata-se, portanto, de observarmos a tradução do estereótipo básico do gaúcho macho e o estereótipo oposto, do gaúcho homossexual passivo, construído pelo simulacro do outro - no caso, o discurso do mineiro.

Notamos que o autor traz certas contribuições importantes para o estudo dos discursos humorísticos no cenário brasileiro. Também Baronas e Ávila (2015), no texto Teoria dos estereótipos básicos e dos estereótipos opostos: a piada levada a sério, trazem contribuições relevantes para o estudo de gêneros humorísticos. Na tentativa de testar a fecundidade das hipóteses teóricas de Possenti (2010), os autores buscam explicitar o que é posto em questão pelas piadas de Joãozinho e descobrir quais os traços que constituem o imaginário social, bem como quais são os lugares comuns com relação àquilo que é posto em questão pelas piadas. Assim, segundo os autores, tais piadas realçam o comportamento masculino, ressaltando questões polêmicas como, por exemplo, o machismo. Baronas e Ávila (2015) destacam alguns lugares-comuns que essas piadas reforçam: Joãozinho é esperto, mal educado, debochado, ignorante, atributos "inerentes" ao homem segundo a ideologia machista. Tudo isso, por sua vez, atravessado pela ideologia machista. Assim como acontece nas piadas de gaúcho, a teoria dos estereótipos básicos e opostos também se concretiza nas de Joãozinho.

Uma vez mais testando a fecundidade das proposições de Possenti (2010), Gatti (2012), em seu texto Personagens infantis: entre o

\footnotetext{
${ }^{4}$ A redução empregada por Possenti se refere a definição mais simples de dicionário: "uma imagem supersimplificada ou convencional de uma pessoa, de um grupo ou de um assunto" (MacMillan Contemporany Disctionary apud POSSENTI, 2010, p. 49).
} 
ingênuo e o ordinário, analisou alguns aspectos específicos de tiras cômicas com personagens infantis. Em seus estudos, aponta que as tiras, ao representar as crianças, exaltam o estereótipo básico da criança ingênua. O autor, ao analisar as tiras cômicas, faz uma aproximação com o gênero humorístico, a piada, sobretudo no que diz respeito às técnicas de construção textual, apontando que os leitores as leem de forma bem parecida. Seu material é composto de tiras da Mafalda, nas quais busca encontrar os possíveis estereótipos da criança. O material mobilizado por Gatti também é composto pela materialidade verbo-visual, não obstante já ser possível observarmos que o uso das imagens - gênero tiras - também contribui para a construção de sentidos.

Os exemplos arrolados, embora ainda pouco numerosos, mostram a pertinência e a relevância da teoria proposta por Possenti (2010) para os estudos do discurso. Com base nessas considerações e seguindo o nosso caminho de investigação sobre o falar caipira nos materiais que selecionamos, testamos tais proposições de Possenti (2010) observando como se constroem os estereótipos básicos e opostos em materiais de ensino de língua portuguesa que tomam a figura do caipira e de seu dialeto como mote de produção de um discurso normativo, isto é, como estereótipos básicos dessa variante do português, que marcam certa cultura, certa variante, que alhures poderia ser considerada como especificamente paulista e a transforma num ponto negativo, associando-a a um falar "errado" - promovendo, ainda, mesmo que de maneira inadvertida, um discurso preconceituoso.

Observamos como esses estereótipos têm sido remodelados em discursos acadêmicos tentando reverter, de certo modo, esse estereótipo oposto criado e divulgado por diferentes materiais didáticos. Dentre eles, estão os planos de aulas e metodologias de ensino do português nas escolas brasileiras. Nossa hipótese é a de que por mais que haja diferentes discussões produzidas sobre a temática caipira e seu dialeto, no âmbito universitário, há uma forte resistência por parte dos produtores de materiais de ensino em divulgar e, sobretudo, incorporar, no sentido de dar corpo, tais diferenças dialetais, corroborando para um modelo de língua utópico e que retoma, de certo modo, a ideia de uma língua transparente.

Conforme enunciamos, nosso objetivo, neste trabalho, é utilizar-se dessa construção de estereotipias, que, atualmente, são difundidas e cristalizadas para promover outro olhar sobre essa variante tão ímpar do sujeito interiorano. Pretendemos incitar, por meio dessas novas contribuições acadêmicas sobre o caipira, uma visão mais ampla sobre esse ator social, corroborando para a promoção de uma identidade brasileira. Ademais, intentamos também mostrar como tais estudos acadêmicos poderiam se tornar materiais de divulgação nas escolas para que o estereótipo oposto atrelado ao falante da língua "errada" possa ser desmistificado.

\section{DAS (DES)CONSTRUÇÕES DO DIALETO CAIPIRA PARA O ENSINO DE LÍNGUA: UM BREVE ESBOÇO}

Neste tópico, temos como objetivo expor algumas das reflexões acerca da constituição de um estereótipo do caipira e de sua circulação em alguns materiais produzidos para o ensino de língua portuguesa em nossas escolas. Com efeito, nossa empreitada configura-se pela compreensão da circulação, ainda maciça de um estereótipo - oposto - de "desvio", ou até mesmo de um "erro", comparado à língua padrão, isto é, um modelo de língua corrente e imposto por meio da tradição lusitana, corroborando para a dicotomia, incessante, entre o que é "certo" e o que é "errado" da língua portuguesa. Para tal empreendimento, partiremos para a descrição de nosso material.

Mobilizamos incialmente um plano de aula intitulado "UCA - usos e valores do dialeto caipira: atividades de retextualização" (OLIVEIRA; PRAZERES, 2011), disponível, conforme já enunciamos, no Portal do Professor do Ministério da Educação. O plano é composto por uma estrutura curricular a ser seguida e orientações a serem adotadas pelos professores. Além disso, observamos a composição de um guia completo, descrevendo as etapas dos exercícios propostos e o passo a passo dos professores para o cumprimento com êxito das atividades. Partimos, inicialmente, do título do plano, em que se observa que o caipira é central na proposta de aula, retratando as características dessa linguagem tão peculiar do brasileiro e ressaltando, consequentemente, os diferentes estereótipos caipiras - básicos - existentes e circulantes em nossa sociedade. Vejamos um dos tópicos, de número 3 , presentes no item "dados da aula":

(1) Transformar registros orais presentes em histórias em quadrinhos e outras narrativas, apresentadas na modalidade dialetal caipira, em produções escritas adequadas à modalidade padrão da língua portuguesa. 
É possível entendermos, a partir da leitura do enunciado extraído do que supomos ser uma das proposições a ser desenvolvidas na aula, que há diferenças entre a forma escrita e a falada, a proposta de transformação de "registros orais" em "produções escritas", com base num modelo padrão de língua portuguesa, reforça ainda mais um dado tipo estereotipado do caipira: o de falar "errado", aquele que usa o famoso / $/ \mathrm{l}$ " "puxado", a variante retroflexa, do sujeito do interior. Entendemos que ao traduzir o discurso oral para o escrito, segundo a norma culta, cria-se um simulacro oposto do caipira, de que ele comete "erro" de português, segundo um modelo "ideal" de língua e que só por meio da norma, de um modelo culto do português aceita-se a sua inscrição como sujeito letrado. Outra atividade significativa do item "dados de aula" é a retratada no ponto 6 :

(2) Produzir um programa televisivo que aborde elementos do universo rural.

Notamos, nesse excerto, outro estereótipo básico circulante e presente no imaginário social brasileiro: o caipira vive no campo pouco condizente com a realidade brasileira, pois segundo Aguilera e Silva (2015, p.175):

[...] O desenvolvimento social de cidades interioranas do sul de Minas Gerais, de Goiás, de São Paulo e do Paraná, focos da variante retroflexa, vem impulsionando uma nova cultura caipira, ou seja, aquela advinda, na maioria das vezes, dos rodeios e de seus participantes que, apesar de trazerem marcas dos caipiras de outros, ocupam, não raramente, lugares sociais privilegiados, não andam mais de carroças, mas de carros e camionetas do ano, não usam mais roupas remendadas pelo gasto do tempo, mas, sim, orientadas pela moda. E, principalmente, não fazem delongas ao utilizar seu /r/ caipira. Ao lado disso, o forte crescimento de duplas sertanejas e de pessoas famosas detentoras desse rótico, ajudam, gradativamente, na manutenção e quiçá na difusão do /r/ retroflexo.

Nesse sentido, opõe-se a esse estereótipo um dado simulacro de um sujeito caipira incapaz de viver nas cidades, caracterizando-o como um sujeito chucro, mal desajustado a lugares que não lhes seriam próprios no dia a dia. Mais adiante, no plano de ensino em questão, vemos a utilização de um clássico das HQs nacionais, a história em quadrinhos do Chico Bento, personagem criado por Maurício de Souza. No desenho intitulado "Chico Bento em o sabe tudo", uma suposta professora elenca um conjunto de perguntas ao menino que se relacionam com a história do Brasil - "quem descobriu o Brasil?"; "quem rezou a primeira missa?"; "quem foi o pai da aviação?"-, configurando cenograficamente uma espécie de confusão da personagem Chico Bento diante de tais questionamentos produz os seguintes enunciados: "num sei", "num mi alembro"; "sei lá".

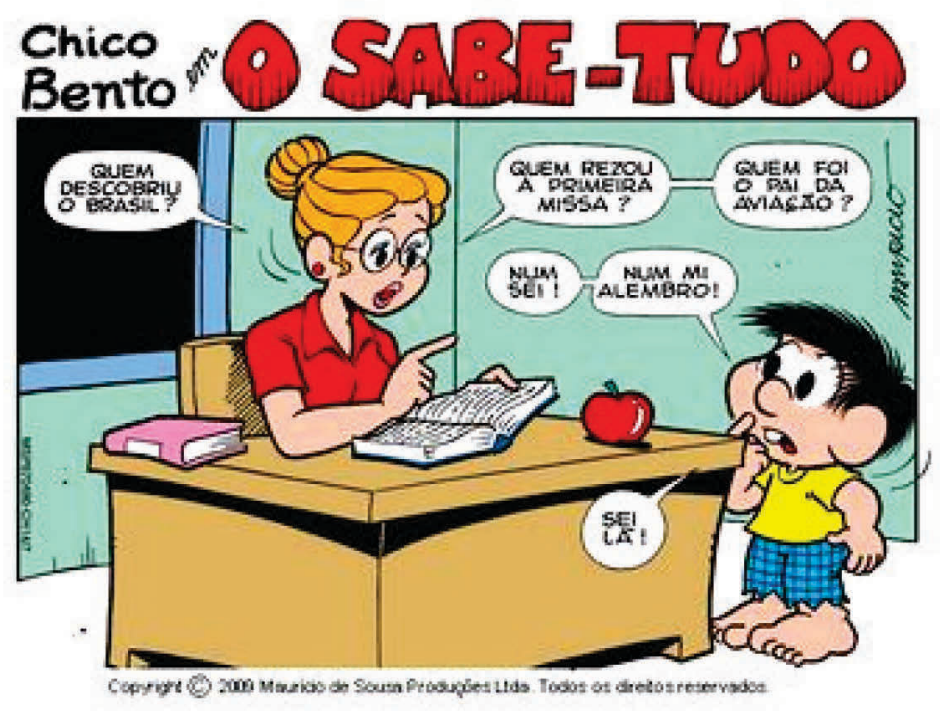

Figura 1: Quadrinho extraído do plano de aula em análise

Fonte: Oliveira e Prazeres (2011)

A tirinha mostra um estereótipo típico do caipira, o de "burro", o de não letrado, reafirmando "[...] imagens pré-construídas e cristalizadas, abreviadas e fatiadas, das coisas e dos seres que o indivíduo faz sob influência de seu meio social" (MORFAUX, 1980 apud AMOSSY, 2004, p. 215). Nota-se, aqui, a confirmação de um estereótipo básico do caipira dado socialmente, aceito, como 
um sujeito do interior e desprovido de conhecimentos sobre os saberes escolarizados, mas que se materializam na sua língua "errada", criando, em um primeiro momento, um momento de humor, característico do gênero em questão - fazendo sobressair, talvez, uma característica positiva dessa variante; porém, ao mesmo tempo, cria-se, um simulacro invertido, reafirmando e corroborando ainda mais a ideia do caipira ser "burro" e não letrado em saberes letrados.

Se realizarmos na internet uma enquete sobre a história da HQ em questão, veremos que a ênfase do texto não é composta apenas por destacar os preciosismos da língua, mas de mostrar o valor que a cultura caipira representa para aqueles que são definidos como tais. Ou seja, Chico Bento não ganhou um dez - o último slide da história, cortado do plano de aula - por não saber sobre a história do Brasil, independentemente de ele deter outros conhecimentos tão importantes quanto o da história do Brasil; isto é, não importa que ele saiba arar a terra, cuidar do gado. Vejamos:

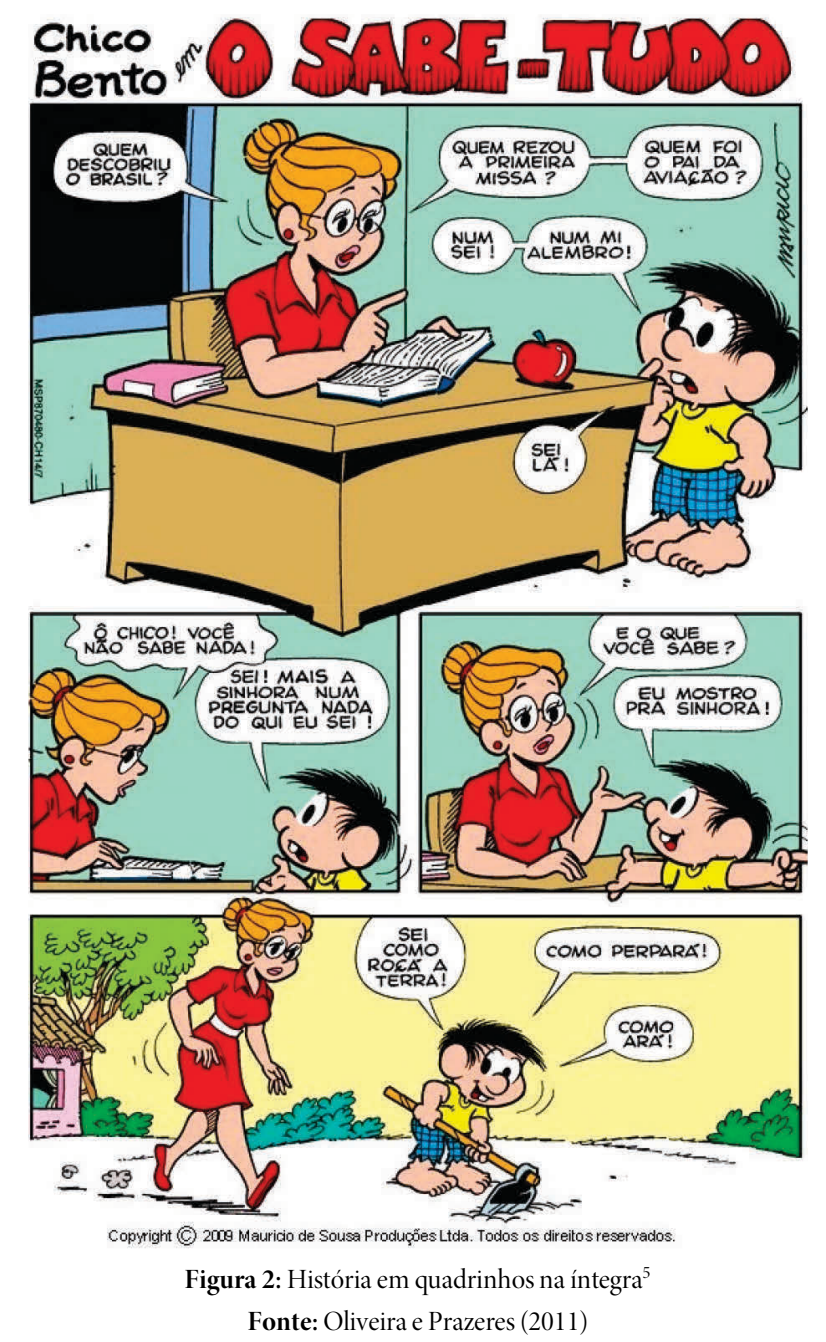

Notamos, portanto, a falta dessa informação no material (com o recorte apenas do primeiro slide), ratificando, desse modo, a ideia inicial de que o caipira, por viver no campo, falar "errado", é "burro". Há, com isso, uma nítida relação de simulacros do sujeito caipira que transforma estereótipos básicos, aqueles cristalizados e circulantes, com valores eufóricos, em estereótipos opostos, corroborando e trazendo um sentido negativo a essa variante, sempre reafirmando um modelo ideal de língua. Passamos para a composição do exercício proposto pelo plano analisado:

(3) Nessa história em quadrinhos, podem ser demarcadas quais expressões estão inadequadas à modalidade padrão. O professor pode sistematizar com os alunos quais são os pontuais desvios: concordância verbal, flexão de plural, "e" com som de "i", supressão de letras e vogais como recursos de economia vocabular presentes no registro 
oral (como em 'quejo' e 'mantega'), substituindo a nomenclatura do verbo no infinitivo pela formação de uma oxítona terminada em “á” ou "ê” ('cuidá', 'ordenhá, 'semeá', 'fazê’), etc.

É possível observar que a proposta, ao dizer que as expressões são "inadequadas à modalidade padrão", considera a variante caipira como um possível desvio da língua, contradizendo a ideia inicial do título acerca dos "usos e valores do dialeto caipira". Ao referenciar traços do dialeto caipira como desvios da língua, num modelo de língua pré-estabelecido, a proposta corrobora para a construção de um simulacro negativo do caipira, isto é, ratifica os estereótipos cristalizados e compartilhados negativamente pela memória coletiva da sociedade brasileira.

Diante dessas primeiras considerações, podemos perguntar: como, então, discutir junto com os alunos a cultura e o dialeto caipira, evitando cair em estereótipos opostos criados pela contínua afirmação de estereótipos básicos? Por meio de um olhar discursivo, procuramos, por conseguinte, discutir a possibilidade de os materiais produzirem discursos, reforçando positivamente a diversidade linguística brasileira, contribuindo para que o preconceito linguístico seja minimizado. Procuramos, igualmente, refletir sobre o estereótipo básico do caipira, aquele proposto pelos materiais de ensino. Contudo, por meio de estudos científicos e acadêmicos, julgamos ser possível promover outros gestos de leitura como meio de ampliar as possibilidades de interpretação e entendimento sobre uma variedade linguística do português significativa e representativa como todas as outras.

Abaixo, elencamos alguns trechos de trabalhos do Projeto História do Português Paulista, o chamado Projeto Caipira, que dentre inúmeros objetivos toma o caipira dentro dos estudos da variação e da mudança linguística. Assim, a possibilidade de levar aos professores de língua portuguesa aspectos históricos, ideológicos e discursivos é que nos instiga a destacar os seguintes recortes:

(4) A concessão de privilégios apenas ao imigrante estrangeiro, na forma de demarcação de lotes para o seu estabelecimento na lavoura, compelia o elemento nacional (os negros e a população livre despossuída) ao status de agregado ou à tarefa árdua do desbravamento do sertão. Marginalizado na sociedade, esse elemento passou a incorporar a imagem de um ser desqualificado, indolente, vadio, conformista, enfim, um ser despreparado para a cidadania, imagem que perpassa a literatura nacional do século XX. (OLIVEIRA; KEWITZ, 2009, p. 211, grifos nossos).

A asserção anterior nos mostra que questões históricas podem ampliar o olhar sobre o caipira, não como preguiçoso, mas como sujeito colocado à margem por representar, juntamente com os escravos libertos, uma ameaça ao imigrante estrangeiro; no trecho, ele é colocado tal qual um escravo, servo que foi levado a cuidar exclusivamente do trabalho braçal. Diante do exposto, é possível afirmar que o estereótipo básico do caipira é fruto de uma construção histórica que pretende desvalorizar todos aqueles que não se inscrevem na estética e no modo europeu de fazer as coisas. Estudos de cunho histórico produzidos em diferentes áreas das Letras e Linguística autorizam uma ressignificação do caipira e sua fala nas aulas de língua, para além do esterótipos básicos e opostos.

(5) De acordo com Antônio Cândido (1973:136), a literatura regionalista contribuiu para o estabelecimento de estereótipos ao focar o homem rural pelo "ângulo pitoresco, sentimental e jocoso" retratando-o a partir da perspectiva europeia. Essa é a opinião de Naxara (1991, p.103), segundo a qual a literatura, em alguns casos, contribuiu para a fixação de estereótipos perigosos a respeito do Brasil e do brasileiro, ainda que se deva reconhecer esforços sérios, não dominantes, no sentido da crítica de tais estereótipos e na abordagem de temas visando a denúncia social'(OLIVEIRA; KEWITZ, 2009, p. 211, grifo dos autores).

Como apontam os autores do excerto acima, é necessário lembrar que vários autores da literatura criaram personagens saturados pelo estereótipo do caipira. Neste trabalho, não é nosso enfoque tratar do posicionamento literário; contudo, cabe enfatizar que é uma perspectiva que reflete histórias, posicionamentos e ideologias distintas e que tomadas redutoramente podem produzir um olhar raso e superficial sobre o caipira e seu dialeto. Observemos os seguintes recortes:

(6) Seguindo essa linha de raciocínio, a mesma autora aponta a vertente negativa do caipira brasileiro criado por Monteiro Lobato, na figura emblemática de Jeca Tatu. Impermeável ao progresso e à civilização, simbolizados 
pela presença do italiano e pela valorização da propriedade, a figura de Jeca Tatu era a de um ser sombrio, sem iniciativa, parasita da sociedade:

"Este funesto parasita da terra é o CABOCLO, espécie de homem baldio, semi-nômade, inadaptável à civilização, mas que vive à beira dela na penumbra das zonas fronteiriças. À medida que o progresso vem chegando com a via férrea, o italiano, o arado, a valorização da propriedade, vai ele refugindo em silêncio, com o seu cachorro, o seu pilão, a picapau e o isqueiro, de modo a sempre conservar-se fronteiriço, mudo e sorna. Encoscorado numa rotina de pedra, recua para não adaptar-se ("Velha Praga", in Urupês, SP 1955:271) (OLIVEIRA; KEWITZ, 2009, p. 211, grifos dos autores).

Esse depoimento de Monteiro Lobato deixa entrever que as características do caipira que ele salienta encontram fundamentam na valorização do modo de vida urbano contra o tradicionalismo agrário, na valorização do estrangeiro (o branco) contra o elemento nacional (o mestiço) (OLIVEIRA; KEWITZ, 2009, p. 211).

Os excertos anteriores nos mostram o quanto a literatura nacional regionalista, como um modo dentre outros de civilizar os costumes e as práticas dos sujeitos, contribuiu decisivamente para a legitimação do caipira como alguém atrasado, preguiçoso, um verdadeiro pária da sociedade. Para além de questões da literatura, há em diferentes mídiuns, outras proposições que podem ser elencadas, tais como a de que a imagem do caipira como "roceiro e ignorante" (AMARAL, 1955 [1920], p. 1), criada a partir de uma elite brasileira da época assim como a concepção do "certo" e do "errado" da língua portuguesa. . Conforme excerto seguinte:

(7) A formação da imagem do desqualificado e a disseminação da visão negativa do caipira, na perspectiva de Manuel Bomfim (1905), foram obras da elite brasileira, que, partindo da contraposição entre o nacional e o imigrante, procurou classificar o povo brasileiro com base no fator racial ou étnico (OLIVEIRA; KEWITZ, 2009, p. 212, grifos nossos).

(8) Assumindo que o estereótipo do 'caipira' formou-se a partir do contraponto que se fez com o elemento estrangeiro, pode-se supor que o atributo 'caipira' dado ao paulista tenha se dado a partir da instalação da Corte no Rio de Janeiro, que, tomava para si os padrões europeus no modo de trajar, de portar-se e de falar. Deste modo, os padrões europeus implantados no Rio teriam servido de contraponto para a definição do paulista como 'caipira' (OLIVEIRA; KEWITZ, 2009, p. 213, grifos nossos).

Ademais, é preciso levar em consideração que o estereótipo básico do caipira parte de uma visão europeia. Em movimentos posteriores traços que compõem esse estereótipo se invertem e são criados outros parâmetros para sua apreciação. Porém, nenhum deles produziu um apagamento dessa imagem que a Literatura ajudou a cimentar. Aqui, não buscamos essa desconstrução, mas a identificação da sua criação, do seu funcionamento e, principalmente da sua atualização, já que o caipira de hoje vai além do seu modo de falar, passou a fazer parte e estar em outros lugares, assumir posições diferentes daquelas préconstruídas, do homem restrito ao campo, por exemplo.

\section{CONSIDERAÇÕES FINAIS}

Como o nosso objeto primeiro de análise foi uma aula de Língua Portuguesa, é necessário ressaltar o quão esse dialeto contribui para a constituição da identidade social dos brasileiros, sobretudo do sujeito interiorano de São Paulo, por exemplo, ressaltando a riqueza cultural do nosso povo. Todavia, como verificamos no plano em questão, a construção das ideias decorre, ainda, da institucionalização de um modelo de língua a ser seguido e da concepção de que toda e qualquer forma linguística que fugir dessa norma culta da língua portuguesa - enquanto uma língua ideal, de cultura - é considerada "desvio", a partir da insistência ad infinitum na dicotomia do "certo" e do "errado". 
O exemplo arrolado é uma pequena parte do que ainda é divulgado pelos materiais de ensino de português aos nossos alunos nas diferentes escolas do Brasil. Não queremos, com isso, questionar o papel do professor em ensinar a norma culta nas escolas, norma essa atrelada à modalidade escrita de alguns dos gêneros que circulam na nossa sociedade; pelo contrário, nosso desejo é instigá-lo a produzir um diálogo interessante entre as pesquisas que são desenvolvidas, no âmbito acadêmico - o discurso científico -, pelos linguistas por meio da proposição de aulas que desmistifiquem tais estereótipos levantados anteriormente, e mais outros tantos difundidos no imaginário social brasileiro, atrelados à modalidade oral. Questionamos, desse modo, a promoção de um ideal de língua ainda frequente no cenário do ensino de português. Ou seja, além de ensinar ao aluno que o fenômeno do rotacismo alteração do 'l' pelo 'r', como na palavra "flor" e "fror”, por exemplo - faz parte das regras do português, é preciso apontar, também, que se trata de uma variante falada numa certa região do Brasil, em franca expansão como asseveram Aguilera e Silva (2015), retratando certa identidade - caipira - tão própria de nosso país.

Nossa proposta tem como objetivo abrir veredas para questões tão ímpares à história da língua portuguesa no Brasil que carecem, de certo modo, de maior atenção quando ensinadas aos nossos jovens nas escolas brasileiras. Torna-se salutar, dessa maneira, demonstrar que os diferentes estereótipos básicos validados pelos materiais reforçam um dado preconceito sobre o falar caipira, produzindo simulacros ainda piores desse sujeito interiorano, que representa certa identidade - de uma diversidade - presente em nosso país.

Propomos, diante de tais questões, aproximações de professores e especialistas da sociolinguística e da dialetologia, por exemplo, para que as diferentes questões, desenvolvidas no contexto acadêmico, cheguem aos nossos alunos, expandido seu imaginário social acerca do dialeto caipira e promovam reflexões que manifestem outros ideais sobre esse sujeito não mais restrito ao €ampo, mas pertencente à cultura brasileira.

A fim de que os professores possam discutir tais questões estereotípicas acerca do caipira e de seu dialeto, levantando as imagens e as cristalizações desse sujeito na sociedade brasileira, propomos a seguir algumas possíveis atividades: ao apresentar o tema da aula, o professor pode, em uma primeira atividade, propor aos alunos elencarem os possíveis estereótipos básicos do caipira e do seu caráter típico regional, ressaltando que o exercício é para que certas palavras ou termos dessa variante possibilitem a reflexão e identificação de possíveis imagens socialmente construídas e aceitas em nossa cultura. Como exemplo de materiais para essa atividade, os estudantes podem buscar tirinhas cômicas, piadas, histórias em quadrinhos - do Chico Bento ou Cebolinha - com o objetivo de observar no discurso a promoção do estereótipo. Após o levantamento, o professor apresenta aos alunos as discussões sobre as variantes do português caipira, presentes na literatura, e que tipos de preconceito tais estereótipos reverberam para a construção da identidade regional caipira. A nosso ver, tal deslocamento possibilita mostrar, durante as aulas, que apesar das imagens consensualmente impostas, trata-se de uma variante do português, importante para construção da própria identidade nacional brasileira.

Outro modo de difundir esse outro olhar sobre o caipira sem, todavia, reduzi-la a traços negativos, seria aproximando tais estereótipos construídos com pesquisas atuais sobre o sujeito caipira e o seu dialeto, desenvolvidas, sobretudo, nas diferentes universidades brasileiras. A Linguística Aplicada tem se dedicado a temas como esses, em que busca suscitar questões da regionalidade brasileira no ensino e, com isso, compreender o seu papel para a história da língua portuguesa. Em virtude disso, incentivar os estudantes a procurarem mais informações sobre tais pesquisas acadêmicas para que "desvendem" certos convencionalismos torna-se uma tarefa interessante, que recomendamos fortemente. Com efeito, sugere-se a elaboração de entrevistas com professores universitários sobre a temática, para logo em seguida, se transformarem em objeto de reflexão nas salas de aula. Por conseguinte, ao se deparar com os fenômenos linguísticos que caracterizam tal dialeto, o professor de português pode ressaltar as diferenças entre o aspecto oral e o escrito da língua, elencando as diferenças e, sobretudo os movimentos que insistem em associar à oralidade o julgamento de língua "errada". Tal contribuição dos discursos universitários sobre a nova configuração do caipira emerge tanto para positivar e quanto buscar uma identidade nacional e, portanto, altera os (d)efeitos de sentido sobre a concepção e o entendimento do que seria o dialeto hoje.

Nossas propostas, por fim, têm como objetivo instigar os professores a promoverem uma maior discussão sobre o dialeto caipira no Brasil e todo o conjunto de características que o define, sem, no entanto, enaltecer certos preciosismos do português marcados 
pelo que é "certo" ou o que é "errado". Não esgotamos, com isso, tais discussões; apenas estimulamos os interessados em (re)descobrir os regionalismos por meio de novos caminhos em que os estereótipos do caipira não apenas assumam traços negativos, como um sujeito do campo, que fala "errado", mas que produza novas reflexões críticas em torno de sua língua, reconhecendo o papel dos estudos da variação, da mudança e do discurso na descrição/interpretação das diferentes variantes linguísticas brasileiras.

Entendemos que este artigo, além de suscitar várias questões no âmbito da linguística e do ensino, nos deixa pelo menos dois saldos positivos. O primeiro tem a ver com a possiblidade de mobilizar a proposta de Possenti (2010) sobre os estereótipos básicos e estereótipos opostos, engendrada pelo autor brasileiro para dar conta de piadas, no tratamento de dados que a rigor não são humorísticos, como é o caso do Plano de Aula do MEC, anteriormente analisado. Com efeito, as atividades propostas pelo Plano, ao se centrarem na adequação da modalidade dialetal caipira à modalidade escrita padrão da língua portuguesa, para além de não reconhecerem o dialeto caipira com o estatuto de uma variedade do português brasileiro, (re)colocam em circulação o estereótipo do sujeito caipira como burro, atrasado etc. O segundo, por sua vez, aposta na integração dos saberes científicos produzidos pela linguística acerca do falar caipira - sua história, seus usos, sua geografia etc - aos saberes sobre o ensino de língua, de maneira a não somente valorizar essa variedade do português, mas sobretudo de incorporar, dar corpo a esse modo de falar.

\section{REFERÊNCIAS}

AGUILERA, V. de A.; SILVA, H. C. Uma nova configuração do Caipira: ecos do /r/ retroflexo. Revista da Abralin, v.14, n.1, p. 171-194, jan./jun. 2015.

AMARAL, A. O dialeto caipira: gramática vocabulário. São Paulo: Anhembi, 1955 [1920].

AMOSSY, R.; PIERROT, A. H. Estereotipos y clichés. Traducción y adaptación: Lelia Gándara. Buenos Aires: Eudeba, 2001. Ed. original: 1997. (Enciclopedia Semiológica).

AMOSSY, R. Estereótipo. In: CHARAUDEAU, P.; MAINGUENEAU, D. Dicionário de análise do discurso. São Paulo: Contexto, 2004 [2002]. p. 213-216.

AZEVEDO, I. O. Chico Bento sabe tudo. Blog de Iris Oliveira Azevedo. 2015. Disponível em: http://irisoliveiraazevedo.blogspot.com/2015/05/chico-bento-em-o-sabe-tudo.html. Acesso em: 15 set. 2018.

BARONAS. R. L. Estudos discursivos à brasileira: uma introdução. Campinas: Pontes Editores, 2015.

BARONAS, R. L.; ÁVILA, F. G. O. Teoria dos estereótipos básicos e dos estereótipos opostos: a piada levada a sério. In: BARONAS, Roberto Leiser (org.). Estudos discursivos à brasileira: uma introdução. Campinas: Pontes Editores, 2015. p. 95-118.

BONFIM, M. A América Latina-Males de origem. Rio de Janeiro, Paris: H.Garnier, Livreiro-Editor, 1905.

CANDIDO, A. Presença da literatura brasileira. 5.ed. revis.São Paulo: Difusão Européia do Livro, 1973.

CANDIDO, A. Os parceiros do Rio Bonito: estudo sobre o caipira paulista e transformação dos meios de vida. 10.ed. São Paulo: Editora 34, 2001.

GATTI, Márcio Antonio. Personagens infantis: entre o ingênuo e o ordinário. Revista Estudos Linguísticos, São Paulo, v.41, n.3, p. 1028-1038, set-dez 2012. Disponível em: http://www.gel.org.br/estudoslinguisticos/volumes/41/el.2012 v3 t10.red6.pdf. Acesso em: 07 fev. 2019.

MAINGUENEAU, D. Gênese dos discursos. Trad. Sírio Possenti. São Paulo, SP: Parábola Editorial, 2008 [1984].

Fórum linguistic., Florianópolis, v.16, n.4, p.4316-4327, out./dez. 2019. 
MAINGUENEAU, D.; CHARAUDEAU, P. Dicionário de análise do discurso. São Paulo, Contexto, 2008.

NAXARA, M. R. Estrangeiro em sua própria terra: representações do trabalhador nacional. 1991. Dissertação (Mestrado) Universidade Estadual de Campinas, Campinas, 1991.

OLIVEIRA, M.; KEWITZ, V. A representação do caipira na imprensa paulista do século XIX. In: Para a história do português brasileiro. CASTILHO, A. Campinas: Unicamp, Publicações IEL, 2009. p. 209-236.

OLIVEIRA, R. S. ; PRAZERES, L. UCA - Usos e valores do dialeto caipira: atividades de retextualização, 2011. Disponível em: http://portaldoprofessor.mec.gov.br/fichaTecnicaAula.html?aula=32327. Acesso em: 5 set. 2019.

POSSENTI, S. Humor, língua e discurso. São Paulo, SP: Contexto, 2010.

POSSENTI, S. Os humores na língua: análise linguística de piadas. Campinas, SP: Mercado de Letras, 1998.

\section{() (1) $\circledast$}

